Article

\title{
Business Intelligence Issues for Sustainability Projects
}

\author{
Mihaela Muntean \\ Business Information Systems Department, Faculty of Economics and Business Administration, West University \\ of Timisoara, 300223 Timisoara, Romania; mihaela.muntean@e-uvt.ro
}

Received: 30 December 2017; Accepted: 23 January 2018; Published: 29 January 2018

\begin{abstract}
Business intelligence (BI) is an umbrella term for strategies, technologies, and information systems used by the companies to extract from large and various data, according to the value chain, relevant knowledge to support a wide range of operational, tactical, and strategic business decisions. Sustainability, as an integrated part of the corporate business, implies the integration of the new approach at all levels: business model, performance management system, business intelligence project, and data model. Both business intelligence issues presented in this paper represent the contribution of the author in modeling data for supporting further BI approaches in corporate sustainability initiatives. Multi-dimensional modeling has been used to ground the proposals and to introduce the key performance indicators. The démarche is strengthened with implementation aspects and reporting examples. More than ever, in the Big Data era, bringing together business intelligence methods and tools with corporate sustainability is recommended.
\end{abstract}

Keywords: corporate sustainability; business intelligence; multi-dimensional data model; key performance indicators

\section{Introduction}

Corporate sustainability (CS) is "a business approach that creates long-term shareholder value by embracing opportunities and managing risks deriving from economic, environmental and social developments" [1]. Sustainable organizations are capable of maximizing their market value in the short, medium, and long term by managing knowledge and all kind of economic, social, and environmental issues [2,3]. When analyzing the sustainability of a company, the following three dimensions are taken into account: social, environmental, and economic aspects. Business decisions should imply a balance among these dimensions. According to Boyer et al. [4] and Farver [5], business intelligence (BI) frameworks are sustaining the decision-making processes in various business contexts. Driving business performance is possible through business analysis, enterprise reporting, and performance management-all three together are the pillars of the BI framework [6].

Nowadays, performance management systems also cover sustainability. Balanced scorecards, dashboards, and metrics include sustainability measurement items $[7,8]$. Therefore, sustainability performance can be measured with the support of BI [9]. Key performance indicators (KPIs) for measuring sustainability projects performance have been proposed, with a relevant example introduced in a paper by Lee and Saen [10].

BI frameworks that allow complex analytical processing and reporting are nowadays identified as business analytics (BA) frameworks. Skills, technologies, and practices for continuous iterative exploration and investigation of past business performances to gain insight and drive business planning are used [11]. Exploration of data from many source systems implies the formulation of an integrated multi-dimensional data model that can embrace various implementations. New technologies reduce the complexity of the data layer moving to in-memory approaches. Practically, the BA tool is both an 
analysis and reporting tool that operates on an in-memory multi-dimensional data model (usually named in-memory database).

In order to support performance management, any BI/BA approach can be enriched with a sustainability dimension for measuring the effort made in this direction. The integration of the sustainability view into a classical BI/BA schema is based on measures and dimensions reengineering. A démarche for defining a BI/BA schema with enriched sustainability measures will be subject to debate.

Sustainability projects are challenging ones. Monitoring them during their execution can also be performed with a BI approach. Monitoring is based on a set of key performance indicators, which have been modeled into a multi-dimensional schema, and further viewed and analyzed by a BA tool [2]. Sustainability implementation, monitoring, and reporting will suffer from transformations due to the changes of technology and information systems. Realizing the potential of big data, companies are interested in exploring this multitude of data and extracting valuable knowledge from it. As a result, firms are investing in business intelligence approaches and are using big data analytics to generate 'big picture' reporting.

\section{Integrating the Sustainability View into a BI Data Model}

Any BI model used by a company can be enriched with a sustainability dimension. KPIs for measuring sustainability performance are added to the classical schema. The new data model can be obtained using the following approach framework (Figure 1):

Step 1. The initial fact table will be transformed into a dimension-Old_Fact_Now_Dimension; as a result, the measures of the classical BI model will become dimensional attributes-AM_1, $A M \_2, \ldots$, $A M \_m$; based on this transformation the sustainability perspective of the whole approach can be modeled as an add-on facility of the classical schema;

Step 2. Three new dimensions will be introduced: Economic profitability and transparency, Social responsibility, and Environmental sustainability;

Step 3. The measures of the sustainability data model will be established; they will be aggregated with respect to the new dimensions_-Old_Fact_Now_Dimension, Time_sustainability, Economic profitability and transparency (EPT), Social responsibility (SR), and Environmental sustainability (ES).

Good sustainability performance can be achieved only if sustainability initiatives and projects are part of the corporate business strategy. Therefore, the sustainability performance management system should be handled within the framework of the corporate performance management system, taking into account the environmental, social, and economic aspects. The KPIs approach implies the inclusion of the sustainability KPIs into the corporate performance management system. The sustainability KPIs should be modeled as measures, if possible, or, should be deduced from the defined measures.

The proposed data model is developed by extending the corporate data model with sustainability specific data. The sustainability measures are stored in three fact tables that have two common dimensions-Old_Fact_Now_Dimension and Time_sustainability. Old_Fact_Now_Dimension is a degenerative dimension that was derived from a previous fact table of an initial, traditional BI approach. It provides a direct reference back to the transactional system and to the traditional BI data model. Time_sustainability dimension brings time intelligence into the model. Sustainability KPIs are stored directly into the fact tables; the overall business KPIs are deduced from the actual dimensional attributes of the degenerative dimension similar to the classical BI schema.

Based on Lee and Saen [10], we have considered economic profitability and transparency (EPT), social responsibility (SR), and environmental sustainability (ES) for covering the sustainability performance landscape.

In terms of economic profitability and transparency (EPT), for covering corporate governance (CG) performance and corporate transparency and accountability (CTA), four KPIs were introduced [10]: number of board/stakeholders meetings (CG1); personnel costs of communication/meetings (CG2); material costs like design/printing costs of communication (CTA1); and finally, personnel/administrative costs (CTA2). 


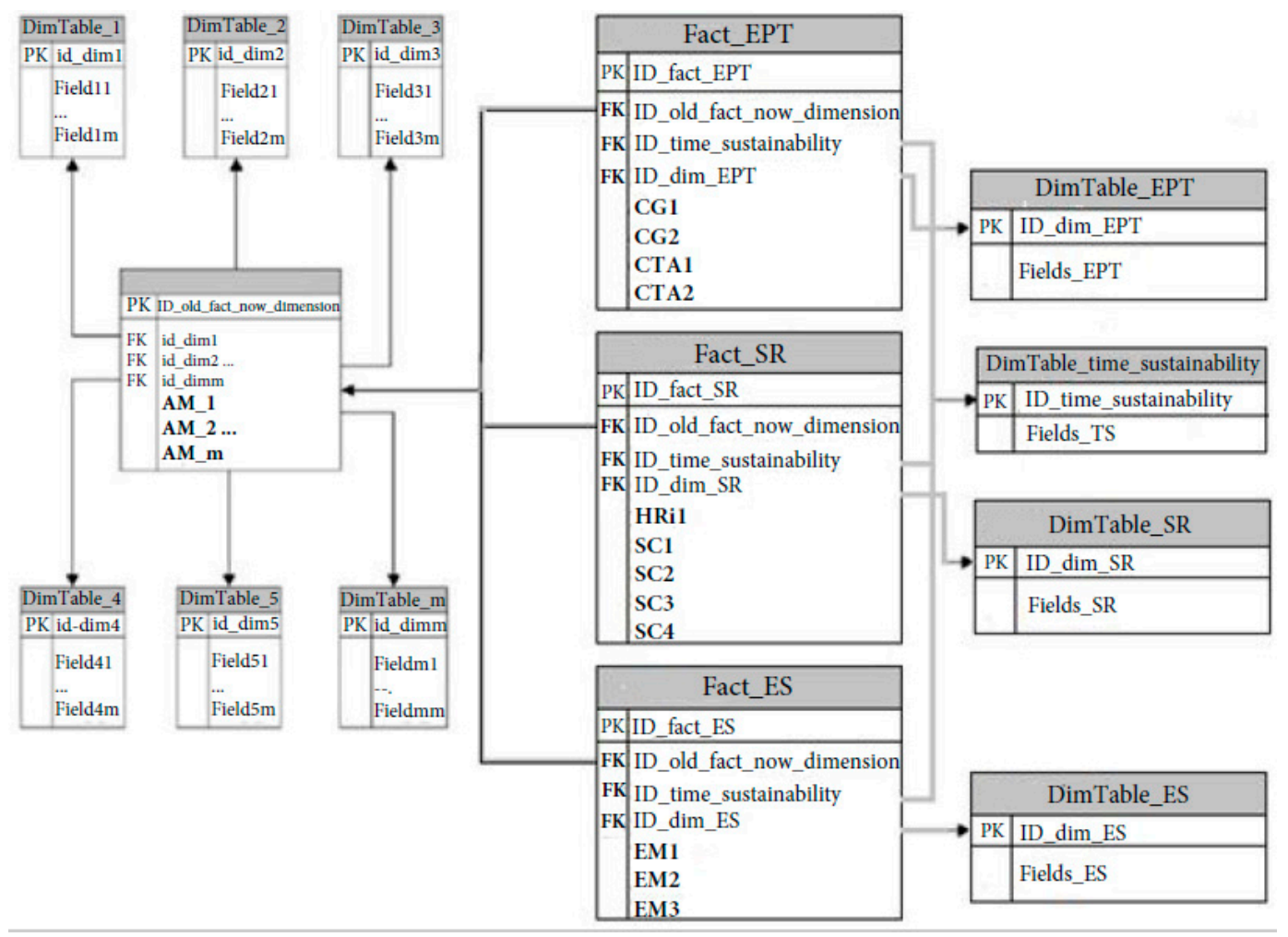

Figure 1. Data model proposal. Integrating sustainability into a business intelligence (BI) approach.

The Social responsibility dimension implies human rights (HRi) aspects and social contribution (SC) related activities. To measure performance, we proposed a mini-set of KPIs: number of employee training hours for corporate social responsibility (HRi1); expenses to train and promote social responsibility (SC1); number of social events with local communities (SC2); amounts of donations (SC3); and volunteering hours/personnel costs (SC4).

In addition, the third dimension, environmental sustainability, is related to environmental management and innovation (EMI) performance based on the following KPIs: number of green technology development projects (EMI1); costs of environmental management (EMI2); and costs of environmental product innovation (EMI3).

The above introduced sustainability KPIs have been chosen to support the data model proposal, although other indicator alternatives would also be suitable; their integration should respect the schema in Figure 1.

In conclusion, sustainability performance management approaches are implying, from a business and data management point of view, the following:

Step 1: analyzing the existing performance management system (BI project);

Step 2: identifying the current KPIs and their dependencies;

Step 3: analyzing the conceptual data model: identifying existing measures and dimensions of the multidimensional view; understanding the implementation details: fact tables and dimensional tables;

Step 4: designing the sustainability performance schema: defining sustainability dimensions-Economic profitability and transparency (EPT), Social responsibility (SR), and Environmental sustainability;

Step 5: defining sustainability KPIs for the considered sustainability aspects;

Step 6: designing the new data model schema similar to the proposal in Figure 1;

Step 7: establishing all reengineering aspects for transforming a fact table of the initial data model into a dimension-Old_Fact_Now_Dimension;

Step 8: establishing all information technology aspects and software procedures for making the BI data model enriched with the sustainability view viable. 
The proposed démarche can be applied to any other set of sustainability KPIs.

\section{Monitoring Sustainability Projects}

Project execution monitoring can be designed into a business intelligence paradigm [12]. Sustainability projects, including sustainability performance management projects such as the approach of integrating the sustainability view into a BI data model, are challenging projects that employ different activities and various resources in order to achieve the desired objectives.

The initiative described in Section 2 has as its main objective the design of a data model that integrates sustainability performance measures into the corporate performance data model. The project itself implies a business intelligence approach based on eight main activities, indicated as Steps 1-8. The obtained output at the end of each step, representing the objective of that activity, will be used as the input for the next step. According to Kerzner [13], project execution monitoring involves monitoring scope, the schedule progress, and the project budget. In Figure 2, we propose a multi-dimensional data model for grounding any initiative of project execution monitoring.

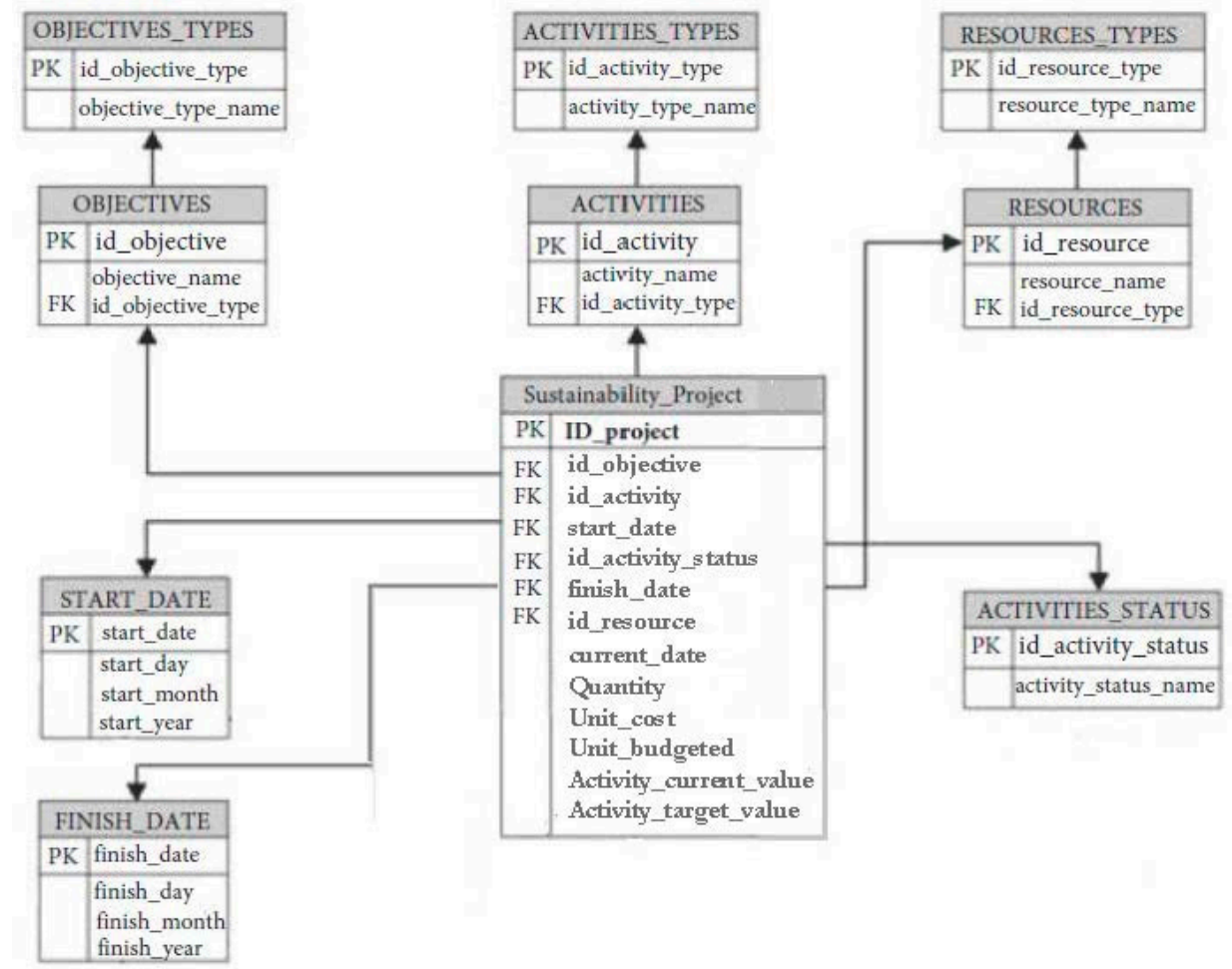

Figure 2. Data model for monitoring sustainability projects.

Key performance indicators can be easily attached to the data model. The following KPIs have been considered [14]: 1—schedule progress: Activity normal average (ANA), Activity normal value (ANV), Activity current average (ACA), Activity average progress (AAvP), Activity absolute progress (AAbP); 2-monitoring the budget: Activity total cost (ATC), Activity total budgeted (ATB), Activity remaining budgeted (ARB); 3-monitoring the scope: Project activities on scope (PAS), Project activities out of scope (PAoS), and Project activities number (PAN). They are calculated directly from the measures (Quantity, Unit_cost, Unit_budgeted, Activity_target_value, Activity_current_value) and have been subject of the author's previous work [14].

The data model in Figure 2 can be integrated into the global corporate data model by applying a reengineering approach to transform a fact table of the former global model into a degenerative dimension (Old_Fact_Now_Dimension) of the monitoring data schema. 


\section{Data Model Implementation Aspects. Support for BI}

Data modeling is the process of creating a data model by applying a data model theory to create a data model instance. The goal of the data model is to make sure that the all data objects required by the database are completely and accurately represented. Data models describe data for further storage in a data management system. According to Bill Inmon's paradigm [15]: "A multi-dimensional database is one part of the overall BI system. An enterprise has one multi-dimensional database (data warehouse-DM), and optional, further data marts extract their information from it".

Both proposals have been introduced as extensions of an existing BI data model. This implies warehousing procedures for deploying the data models. The démarche is based on Inmon's approach-the top-down design [15]. The goal consists of modeling a subject-oriented, time-variant, integrated DM by passing through Steps 1-8 introduced in Section 2.

Reengineering aspects regarding the implementation of the KPIs and the realization of the degenerative dimension depend on the implementation technology. The degenerative dimension Old_Fact_Now_Dimension is derived from a fact table of the initial corporate data model. For example, MS SQL Server and its services offer full assistance in defining the degenerative dimension [16]. Referring to KPIs, technically they are collections of calculations (a combination of multidimensional expressions (MDX) and calculated members) associated with measures groups in the multi-dimensional data model.

The process of defining a KPI implies establishing a measure group, a value expression, a goal expression, a status indicator and expression, and a trend indicator and expression. Finally, all KPIs are included into a balanced scorecard. Results obtained after implementing the sustainability view are presented in Figure 3, where the first group of KPIs is listed. For KPIs with a "negative connotation" [17], the goal represents a maximum accepted value for considering the existence of a good performance status. Thereby, the status expression, for example, for CG2, has been formulated as the following

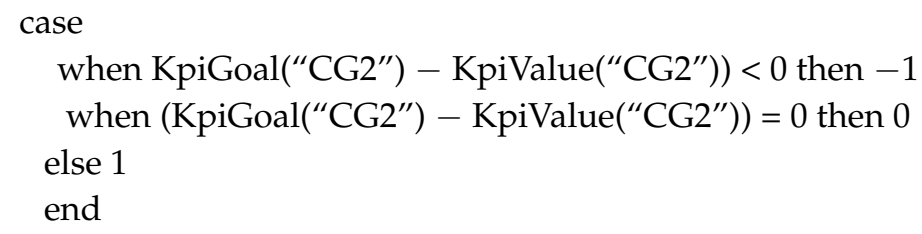

\begin{tabular}{|c|c|c|c|c|c|}
\hline Economic profitability and transparency & Value & Goal & Status & $\begin{array}{c}\text { Previous } \\
\text { Value }\end{array}$ & Trend \\
\hline Number of board/stakeholders meetings & 14 & 10 & X & 12 & 수 \\
\hline Personnel costs of communic/meetings & 180 & 160 & X & 204 & $\forall$ \\
\hline Material costs (design/printing costs) & 60 & 47 & X & 40 & $\mathbf{1}$ \\
\hline Personnel/administrative costs & 170 & 175 & $\checkmark$ & 180 & $\checkmark$ \\
\hline
\end{tabular}

Figure 3. BI approach. Output example of the first data model implementation.

The value -1 stands for the worst performance, 0 for neutral, and 1 for best, with the performance reflected by the status visual indicator.

According to the data model proposed for monitoring project execution, the KPIs for monitoring the budget can be calculated with the following formulas

$$
\begin{aligned}
& \text { ATB }=\text { Unit_budgeted } \times \text { Quantity, } \\
& \text { ATC }=\text { Unit_cost } \times \text { Quantity, } \\
& \text { ARB }=\text { ATB }- \text { ATC, }
\end{aligned}
$$


transposed in

[Measures]·[Unit_budgeted] $\times$ [Measures].[Quantity],

[Measures]·[Unit_cost] $\times$ [Measures].[Quantity],

([Measures]·[Unit_budgeted] - [Measures].[Unit_cost]) $\times$ [Measures]·[Quantity].

For monitoring the budget during the project execution, milestones have been established. In Figure 4, twelve weeks after the project has started, the overall status has been analyzed; also, for each activity, the above KPIs have been determined and analyzed. Analyzing ARB, the budgeting will be analyzed and the corresponding visual status indicator displayed. Although for activity A1, the actual costs are greater than the estimated budged for this activity, the overall estimation is satisfactory. For the last week, we have an ARB of 738, which should cover the cost of the unfinished tasks of activity A3. According to the timeline, the status can be 'started', 'in progress', or 'completed'.

\begin{tabular}{|l|r|r|r|r|r|r|}
\hline Activity & ATB & ATC & ARB & Milestone & $\begin{array}{c}\text { Timeline } \\
\text { (weeks) }\end{array}$ \\
\hline A1 & 1200 & 1500 & -300 & 4 & 4 completed & $\sim$ \\
\hline A2 & 3000 & 3000 & 0 & 5 & 5 completed & $\sim$ \\
\hline A3 & 3256 & 2217 & 1038 & 3 & 4 in progress & $\sim$ \\
\hline
\end{tabular}

Figure 4. BI approach. Output example of the second data model implementation. ATB: Activity total budgeted; ATC: Activity total cost; ARB: Activity remaining budgeted.

Theoretical extensions of the data models together with implementation aspects in different business environments will be subjects of further research.

\section{Discussion}

Both business intelligence [18-20] and corporate sustainability [21-23] are two themes that have been highly studied in scientific literature. Business intelligence is an umbrella term for various business managing processes based on well informed decisions, which lead to high performance levels within organizations. Considered the art of gaining business advantages from data, BI covers verticals like 'Business Analysis', 'Enterprise Reporting', and 'Performance Management'. Traditionally, BI applications allow users to acquire knowledge from a company's internal data through various technologies. Companies now have access to different kinds of data that are collected from various sources including websites, business applications, social media pages, mobile devices, documents, and archives, all of them together identified as big data. The 'explosion of data', referring to the volume, variety, and velocity of the existing data, involves new forms of BI [18,19].

According to Getz [24], "sustainability is the ability to keep an organization running indefinitely without depleting natural resources or impacting the environment, maintaining economic viability, and conducting fair business practices with human capital". Furthermore, corporate sustainability is a business approach that creates long-term shareholder value by embracing opportunities and managing risks deriving from economic, environmental, and social developments. The sustainability triangle, a conceptual framework for corporate sustainability, aims at economic, eco-, and socio-effectiveness by integrating and linking the economic, environmental, and social dimensions through the concepts of eco-efficiency, socio-efficiency, and eco-justice [9,22]. Theoretical approaches and best practices in measurement, management, and reporting are indispensable for sustainability performance [21,23].

Despite this, only a few studies have approached these two themes in an interdisciplinary démarche. Referring to relevant initiatives [2-4,7,8], we have identified arguments on how BI methods and tools can improve the gathering, analysis, and dissemination of business data among employees, clients, suppliers, and partners, including corporate sustainability information. With respect to 
performance management principles, sustainability KPIs have been proposed $[9,10]$ and included in balanced scorecards, with the theoretical fundamentals being part of a business intelligence framework [11,12]. Methodologies for measuring sustainability performance and models for measuring corporate sustainability have been proposed and tested, with the debate being developed with respect to the "From-Data-to-Performance" value chain, similar to business intelligence [6]. In summary, the efforts have been made preponderant on business issues, on integrating sustainability management into the corporate performance management system, bringing together business intelligence methods, and corporate sustainability.

However, business models without the support of technology and information systems are not viable. Therefore, the conjunction of business intelligence and sustainability implies beyond the integrated business model, the support of information technology. An integrated multi-dimensional data model would solve most of the integration challenges [25].

We reinforce our opinion that the management of corporate sustainability implies the use of business intelligence methods and tools for analyzing the financial, environmental, and social dimensions of the business [24]. Previous research by the author $[6,20]$ has been focused on some theory and practice issues in business intelligence, with the BI value chain being introduced in terms of a value proposition [26]. Raw data is extracted from different data sources, further integrated into a multi-dimensional data model, which is nowadays usually stored in an "in-memory database". Through analytical processing, knowledge is retrieved from the database in order to support various decision-making processes. Data analytic tools (data analytics/business analytics) are capable, based on the multi-dimensional data model, of performing the necessary processing and reporting to support smart decision making, innovative services, new business models, innovation, and sustainability projects.

Both business intelligence issues presented in this paper represent the contribution of the author in modeling data for supporting further BI approaches in corporate sustainability initiatives. In developing any BI démarche, the design of the data model is crucial for the deployment of the system.

In Romania, most companies have implemented business intelligence systems that are capable of supporting the entire BI value chain: extracting data from data sources, integrating data into the multi-dimensional database, performing business analysis, and generating reports for managers and supporting performance management programs. The last three or four years have marked a change from the traditional BI approaches to the business analytics (BA) based ones [27]. At the same time, first steps have been made into integrating sustainability in business strategies [28,29]. In this context, the demand for reengineering the in-memory database of the existing BI/BA systems is strongly necessary.

Not least, best practices in project management reinforce the importance of monitoring project execution. It turns out that project management is $20 \%$ planning and $80 \%$ monitoring and control [30]. Remaining in the field of data model proposal, a multi-dimensional schema for monitoring sustainability projects is being introduced.

The two data models are not isolated data structures; thanks to the degenerative dimension Old_Fact_Now_Dimension, they are part of the corporate data model, which is, in fact, a big data model.

Despite the effervescence of unstructured data, for example, data gathered from websites, social media pages, and documents, the relational and multi-dimensional data model is still en vogue in corporate and business environments for its capability to model large data sets, commonly referred to as big data. The "in-memory database" technology extends the capability of the database management systems to store huge volumes of data. As mentioned in a recent article [31], dimensional models (multi-dimensional models) are present in the Big Data era. Data marts (departmental data warehouses) are still stored on relational or multi-dimensional platforms, and some companies have also chosen to move into the cloud. Thereby, multi-dimensional modeling approaches are still relevant, and the innovative approach presented in the paper fits in the big data landscape. 
Both data model proposals can have a finality in their implementations; BI/BA have highly integrating capabilities and get the most value from big data. Theoretical extensions of the data models together with the implementation of aspects from a particular business environment will be the subject of further research.

\section{Conclusions}

Companies have implemented various business intelligence approaches in order to sustain performance management. All these initiatives are capable of extracting data from different sources, internal or external, to integrate it into a unitary model for further advanced business analysis and reporting. Relevant information is extracted and delivered to decision makers as valuable knowledge. In big data environments, BI embraces new forms, and BI tools, now evolved into big data analytics, are capable of gaining insight into this large volume of data. According to Forbes, in 2017, 53\% of companies adopted big data analytics [32]. Both structured and unstructured data is processed, and descriptive, predictive, and even prescriptive analysis is performed. Despite the effervescence of the of unstructured data, coming from documents, the web, social networks and communities, the structured component of big data is and will remain an important data source for the BI/BA systems. Citing Columbus [32], "the dimensional (multi-dimensional) model becomes the nexus of a holistic approach managing BI, analytics, and governance programs".

Existing BI projects in enterprises need to be extended in order to integrate corporate sustainability approaches. A first step of the démarche consists in adapting the multi-dimensional data model of the BI database. United under Business Intelligence Issues for Sustainability Projects, the proposed data models can substantiate any initiative in this domain.

In a top-down approach, from business strategy to underlying data, the following statements represent essential pillars: sustainability is part of the business strategy; sustainability performance management is integrated into the corporate performance management system; the corporate BI system also includes the sustainability dimension; the sustainability data model is integrated into the corporate data model, and sustainability data is part of the corporate data.

Author Contributions: Mihaela Muntean conceived, designed, and wrote this paper.

Conflicts of Interest: The author declares no conflict of interest.

\section{References}

1. Dyllick, T.; Muff, K. Clarifying the Meaning of Sustainable Business: Introducing a Typology from Business-as-Usual to True Business Sustainability. Organ. Environ. 2015, 4, 1-19. Available online: https://www.bsl-lausanne.ch/wp-content/uploads/2015/04/Dyllick-Muff-ClarifyingPubl-Online.full_.pdf (accessed on 21 January 2018). [CrossRef]

2. Petrini, M.; Pozzebon, M. Integrating Sustainability into Business Practices. Braz. Adm. Rev. 2010, 7, 362-378. Available online: http://www.scielo.br/pdf/bar/v7n4/04.pdf (accessed on 21 January 2018). [CrossRef]

3. Dočekalová, M.P.; Kocmanová, A. Composite indicator for measuring sustainability. Ecol. Indic. 2016, 61, 612-623. [CrossRef]

4. Boyer, J.; Frank, B.; Green, B.; Harris, T.; Van de Vanter, K. Business Intelligence Strategy: A Practical Guide for Achieving BI Excellence, 1st ed.; MC Press Online, LLC: Ketchum, ID, USA, 2010; pp. 35-72. ISBN 978-158347-362-7.

5. Farver, S. Mainstreaming Corporate Sustainability: Using Proven Tools to Promote Business Success, 1st ed.; GreenFix, LLC: Aspen, CO, USA, 2013; pp. 133-142. ISBN 978-1484135327.

6. Muntean, M. Business Intelligence Approaches. Math. Models Methods Appl. Sci. 2012, 1, 192-196. Available online: https:/ /mpra.ub.uni-muenchen.de/41139/ (accessed on 21 January 2018).

7. Ahmad, A. Business Intelligence for Sustainable Competitive Advantage. In Sustaining Competitive Advantage via Business Intelligence, Knowledge Management, and System Dynamics; Quaddus, M., Ed.; Emerald Group Publishing Limited: Bingley, UK, 2015; Vol. 22A. 
8. Scholtz, B.; Calitz, A. Using Business Intelligence to Support Strategic Sustainability Information Management. In Proceedings of the 2015 Annual Research Conference on South African Institute of Computer Scientists and Information Technologists, Stellenbosch, South Africa, 28-30 September 2015. [CrossRef]

9. Thomas, M.; McElroy, M.W. A Better Scorecard for Your Company's Sustainability Efforts. Hav. Bus. Rev. 2015. Available online: https:/ /hbr.org/2015/12/a-better-scorecard-for-your-companys-sustainability-efforts (accessed on 21 January 2018).

10. Lee, K.H.; Saen, R.F. Measuring corporate sustainability management: A data envelopment analysis approach. Int. J. Prod. Econ. 2012, 140, 219-226. [CrossRef]

11. Laursen, G.H.N.; Thorlund, J.; DeWees, B. Business Analytics for Managers: Taking Business Intelligence beyond Reporting; John Willey \& Sons: Hoboken, NJ, USA, 2010; pp. 17-42. ISBN 978-0-470-89061-5.

12. Pondel, J.; Pondel, M. BI and Big Data Solutions in Project Management. Bus. Inform. 2015, 4, 55-63. Available online: http://www.dbc.wroc.pl/Content/34362/Pondel_BI_And_Big_Data_Solutions_ In_Project_Management_2015.pdf (accessed on 21 January 2018). [CrossRef]

13. Kerzner, H. Project Management: A System Approach of Planning, Scheduling and Controlling, 11th ed.; John Willey \& Sons: Hoboken, NJ, USA, 2013; pp. 549-573. ISBN 978-1-118-02227-6.

14. Muntean, M.; Cabău, L.G. Business Intelligence Support for Project Management. In Proceedings of the 14th International Conference on Informatics in Economy; 2014; pp. 428-432, WOS: 000362796900069. Available online: https:/ / mpra.ub.uni-muenchen.de/51905/ (accessed on 21 January 2018).

15. Inmon, W.H. Building the Datawarehouse, 4th ed.; Wiley Publishing Inc.: Hoboken, NJ, USA, 2005; pp. 71-138. ISBN 978-0471081302.

16. Webb, C.; Russo, M.; Ferrari, A. Expert Cube Development with SSAS Multidimensional Models, 2nd ed.; Packt Publishing Ltd.: Birmingham, UK, 2014. ISBN 978-1-84968-990-8.

17. Muntean, M.; Cabau, L. Business Intelligence Approach in a Business Performance Context. Austrian Comput. Soc. 2012. Available online: https://mpra.ub.uni-muenchen.de/29914/1/MPRA_paper_29914.pdf (accessed on 21 January 2018).

18. Marz, N.; Warren, J. Big Data: Principles and Best Practices of Scalable Realtime Data Systems; Manning Publishing Co.: Shelter Island, NY, USA, 2015; pp. 27-53. ISBN 978-1-617-290343.

19. Provost, F.; Fawcett, T. Data Science for Business: What You Need to Know about Data Mining and Data-Analytic Thinking, 1st ed.; O'Reilly Media Inc.: Newton, MA, USA, 2013; pp. 81-110. ISBN 978-1-449-36132-7.

20. Muntean, M.; Muntean, C. Evaluating a Business Intelligence Solution. Feasibility Analysis Based on Monte Carlo Method. J. Econ. Comput. Econ. Cybern. Stud. Res. 2013, 47, 85-102.

21. Brockett, A.; Razaee, Z. Corporate Sustainability: Integrating Performance and Reporting; John Willey \& Sons: Hoboken, NJ, USA, 2012; pp. 67-98. ISBN 978-1-118-12236-5.

22. Thiele, L.P. Sustainability (Key Concepts), 2nd ed.; Polity Press: Cambridge, UK, 2016; pp. 90-171. ISBN 978-1509511075.

23. Benn, S.; Edwards, M. Organizational Change for Corporate Sustainability (Understanding Organizational Change), 3rd ed.; Routledge: New York, NY, USA, 2014; pp. 135-180. ISBN 978-0415695497.

24. Getz, A. Using Business Intelligence to Achieve Sustainable Performance. 2014. Available online: http: / / bi-insider.com/wp-content/uploads/2014/10/BI-to-Enhance-Sustainability-2014-10-10.pdf (accessed on 28 July 2017).

25. Džmuráň, M. Introduction to Data Integration Driven by a Common Data Model. Available online: http: / / www.galeos.eu/uploads/Soubory/ClankySOI/Introduction_to_Data_Integration_EN.pdf (accessed on 10 November 2017).

26. Muntean, M. Theory and Practice in Business Intelligence. 2012. Available online: https://ssrn.com/ abstract $=2144440$ (accessed on 21 January 2018).

27. Iovan, S. Business Intelligence and the Transition to Business Analytics. Annals of "Constantin Brâncuşi" University of Târgu-Jiu, Engineering Series. 2014, pp. 150-156. Available online: http://www.utgjiu.ro/ revista/ing/pdf/2014-4/25_Stefan\%20Iovan.pdf (accessed on 21 January 2018).

28. Fistis, G. Demand for Sustainability Expertise on the Rise as Romanian Companies Tune in to European Business Standards. 2015. Available online: http://www.business-review.eu/featured/demand-forsustainability-expertise-on-the-rise-as-romanian-companies-tune-in-to-european-business-standards93203 (accessed on 18 September 2017). 
29. Stancu, M. Romanian Companies Need to Make Swift and Sustained Steps to catch up on Corporate Responsibility Reporting. 2017. Available online: https://home.kpmg.com/ro/en/home/media/pressreleases/2017/10/cr-reporting-2017-survey.html (accessed on 3 November 2017).

30. Berkun, S. Making Things Happen: Mastering Project Management, revised ed.; O'Reilly Media, Inc.: Newton, MA, USA, 2008; pp. 241-301. ISBN 978-0-596-51771-7.

31. Adamson, C. Dimensional Models in the Big Data Era. 12 April 2017. Available online: https://tdwi.org/ Articles /2017/04/12/Dimensional-Models-in-the-Big-Data-Era.aspx?Page=2 (accessed on 26 November 2017).

32. Columbus, L. 53\% of Companies Are Adopting Big Data Analytics. December 2017. Available online: https:/ / www.forbes.com/sites/louiscolumbus/2017/12/24/53-of-companies-are-adopting-bigdata-analytics/\#4f19636c39a1 (accessed on 8 January 2018).

2018 by the author. Licensee MDPI, Basel, Switzerland. This article is an open access article distributed under the terms and conditions of the Creative Commons Attribution (CC BY) license (http:/ / creativecommons.org/licenses/by/4.0/). 